\title{
openheart Randomised trial of the comparison of drug-eluting stents in patients with diabetes: OCT DES trial
}

\author{
Stephen Hamshere, Alex Byrne, Tawfiq Choudhury, Sean M Gallagher, \\ Krishnaraj S Rathod, Julia Lungley, Charles J Knight, Akhil Kapur, Daniel A Jones, \\ Anthony Mathur
}

\begin{abstract}
- Additional material is published online only. To view, please visit the journal online (http://dx.doi.org/10.1136/ openhrt-2017-000705)
\end{abstract}

To cite: Hamshere S, Byrne A, Choudhury T, et al. Randomised trial of the comparison of drugeluting stents in patients with diabetes: OCT DES trial. Open Heart 2018;5:e000705. doi:10.1136/

openhrt-2017-000705

Received 24 August 2017 Revised 10 January 2018 Accepted 18 January 2018
Check for updates

Department of Cardiology, Barts Heart Centre, St Bartholomew's Hospital, Barts Health NHS Trust, London, UK

Correspondence to Dr Stephen Hamshere; stephenhamshere@doctors. org.uk

\section{ABSTRACT}

Background To date, there have been limited comparisons performed between everolimus-eluting stents (EES) and zotarolimus-eluting stents (ZES) in patients with diabetes mellitus (DM). The objectives of this study was to assess the use of second-generation drugeluting stents in patients with DM, using optical coherence tomography (OCT) to compare the level of stent coverage of Boston Scientific Promus Element EES compared with Medtronic Resolute Integrity ZES.(Clinicaltrials.gov number NCT02060357).

Methods This is a single-centre randomised blinded trials assessing two commercially available stents in 60 patients with diabetes (ZES: $n=30$, EES: $n=30$ ). Patients underwent intracoronary assessment at 6 months with OCT assessing stent coverage, malapposition, neointimal thickness and percentage of in-stent restenosis (ISR).

Results Of the 60 patients randomised, 46 patients underwent OCT analysis. There was no difference in baseline characteristics between the two groups. Both Promus Element and Resolute Integrity had low rates of uncovered struts at 6 months with no significant difference between the two groups (2.44\% vs $1.24 \%$, respectively; $\mathrm{P}=0.17)$. Rates of malapposition struts $(3.9 \%$ vs $2.5 \%$, $\mathrm{P}=0.25$ ) and percentage of luminal loss did not differ between stent types. In addition, there was no significant difference in major adverse cardiovascular events $(\mathrm{P}=0.24)$ between the stent types.

Conclusions This study is the first randomised trial to evaluate OCT at 6 months for ZES and EES in patients with diabetes. Both stents showed comparable strut coverage at 6 months, with no difference in ISR rates at 6 months.

\section{INTRODUCTION}

Diabetes mellitus (DM) is a global health issue with the worldwide prevalence of the adult diabetic population projected to reach one-half billion people in 2030. ${ }^{1}$ Patients with diabetes have an increased risk of coronary artery disease as well as an increased risk of mortality and morbidity associated with coronary revascularisation procedures. Furthermore, diabetes is an independent risk factor for worse outcomes following percutaneous coronary intervention (PCI). ${ }^{2}$ Compared with bare metal stents

\section{Key questions}

What is already known about this subject?

- Patient with diabetes mellitus have an increased risk of coronary artery disease (CAD) and treatment with percutaneous intervention. There have been large-scale trials on the use of drug-eluting stents in the general CAD population; however, few studies have targeted patients with diabetes alone.

What does this study add?

- This is one of the first studies to assess the intracoronary development of in-stent restenosis in patients with diabetes after implantation of two different drug-eluting stent types. This study is able to show the degree of restenosis in these stents at 6 months and their association with symptoms/ clinical outcomes.

How might this impact on clinical practice?

- Although there was no clinical difference in restenosis rates between the two stents types, there was a large proportion of patients who had significant in-stent restenosis without symptoms and therefore these findings could change the clinical follow-up of these patients.

(BMS), first-generation drug-eluting stents (DES) markedly decreased the rate of restenosis in patients with diabetes. However, there were safety concerns due to late stent thrombosis (ST) in both patients with diabetes and patients without diabetes. ${ }^{4}$ Drug deliverability was improved in second-generation DES, which have been evaluated in several studies involving patients with diabetes, ${ }^{56}$ although event rates after PCI predominantly driven by patients with insulin-dependent DM are still considerably higher than in patients without diabetes. ${ }^{7}$ The dramatic improvement seen with second-generation stents resulting in the inhibition of neointima formation and delayed vessel wall healing results in incomplete endothelialisation of the stent struts. ${ }^{8}$ Previous autopsy studies demonstrated that 
the most important histological predictors of ST were endothelial coverage and the ratio of uncovered to total stent struts after second-generation DES implantation. ${ }^{9}$

To date, there have been limited comparisons performed between everolimus-eluting stents (EES) and zotarolimus-eluting stents (ZES) in patients with DM. Using a large registry, Park et al compared the Xience EES and Resolute Integrity ZES in 1855 patients with diabetes showing comparable and low incidences of target lesion failure $(3.5 \%)$ and ST $(0.3 \%)$ at 1 year, suggesting excellent safety of both stent types. ${ }^{10}$ In the RESERVOIR (A Randomized Comparison of Reservoir-Based Polymer-Free Amphilimus-Eluting Stents Versus Everolimus-Eluting Stents With Durable Polymer in Patients With Diabetes Mellitus) clinical trial, which compared reservoir-based polymer-free amphilimus-eluting stents (AES) versus EES with durable polymer in patients with DM demonstrated a non-inferiority between the two stent types at the 9-month follow-up $(11.97 \% \pm 5.94 \%$ for AES and $16.11 \% \pm 18.18 \%$ for EES (upper one-sided $95 \%$ CI 2.6, $\mathrm{P}$ for non-inferiority $=0.0003)) .{ }^{11}$ While the majority of DES studies using OCT have failed to demonstrate a significant difference between the two different DES types in DM, a few such as the substudy of the J-DESsERT (Japan-Drug Eluting Stents Evaluation; a Randomized Trial) demonstrated a significantly higher number of uncovered struts within the sirolimus-eluting stent compared with paclitaxel-eluting stent. ${ }^{12}$

The aim of the present study was to assess the use of second-generation DES in patients with DM, specifically using OCT to compare the level of stent coverage of Boston Scientific Promus Element EES compared with Medtronic Resolute Integrity ZES. The study aimed to evaluate the rate of re-endothelialisation at 6 months between EES and ZES. As endothelialisation is a pathological event and therefore cannot be assessed in vivo, the study will assess stent coverage as a surrogate marker of re-endothelialisation.

\section{METHODS \\ Trial}

The aim of this study was to assess the degree of neointimal stent coverage in second-generation DES in a diabetic population. In addition, we aim to assess the clinical and angiographic outcomes of second-generation DES. Patients were randomised in a single-centre trial to receive either ZES (Resolute Integrity, Medtronic) or to EES (Promus Element, Boston Scientific). The trial was performed in accordance with the Declaration of Helsinki (1993) and the principles of the International Conference of Harmonization-Good Clinical Practice guidelines.

\section{Recruitment}

Potential patients were assessed for eligibility prior to undergoing PCI or potential PCI procedures at the Barts Heart Centre. Inclusion criteria included patients aged between 18 and 80 years with known diabetes (type 1 and type 2), who were suitable for DES implantation and OCT imaging. Patients were excluded if they had known renal impairment (creatinine $>200 \mathrm{mmol} / \mathrm{L}$ ), left ventricular ejection fraction below $35 \%$, a lesion that was $>55 \mathrm{~mm}$ long or $<2.5 \mathrm{~mm}$ in diameter, had a contraindication to antiplatelet medication or planned use of BMS.

\section{Randomisation}

After consenting for the trial, patients underwent diagnostic angiography. If angiographically found to be suitable, patients were randomised in a sequential 1:1 fashion either Resolute Integrity ZES (Medtronic) DES implantation or Promus Element EES (Boston Scientific) implantation. Randomisation was performed using dedicated randomisation software prior to the start of the trial and sealed within externally numbered opaque envelopes to conceal the treatment designation. When a consented patient fit all-inclusion criteria, the appropriate numbered envelope would be open during the case within the appropriate catheter lab.

\section{Quantitative coronary angiography assessment}

Quantitative coronary angiography (QCA) analysis was performed prior to stent implantation (to assess the maximal balloon diameter reference), after stent implantation and at 6-month follow-up using an off-line quantitative coronary angiographic system (QAngioXA 7.3 (Medis)). QCA will be analysed in a blinded fashion by two experienced and independent cardiologists and adjudicated by a senior cardiologist, if there are any discrepancies in the analysis.

The automated software will detect the boundaries of a selected coronary vessel segment using digitised and optically magnified sections. However, if an incorrect centreline is chosen because of a side branch, then correction is possible manually. The vessel diameter will be calculated in $\mathrm{mm}$, which will be referenced by using the boundaries of a section of the contrast catheter. To detect the contours of the vessel, the user will indicate the vessel by choosing two centre positions proximal and distal to the area of interest.

All measurements of the target lesion will be obtained in the 'in-stent' zone, which was defined as $5 \mathrm{~mm}$ proximal and distal to each stent edge and across the entire segment. The following QCA parameters will be calculated: reference vessel diameter, minimal lumen diameter, per cent diameter stenosis (difference between the reference vessel diameter and minimal lumen diameter/ reference vessel diameter $\times 100$ ) and late lumen loss (difference between the postprocedure and follow-up minimal lumen diameter).

\section{Intracoronary OCT}

Intracoronary OCT was performed 6 months post-PCI with a commercially available OCT system (St Jude Medical, USA) and OCT imaging catheter (Dragonfly, St Jude Medical, USA). A 6 Fr-guiding catheter was introduced to 
the target coronary artery either by the radial or femoral approach. A standard 0.014-inch guide wire was passed down the target coronary artery and the OCT imaging catheter passed beyond the stented segment. For optimal OCT image capture, coronary artery preparation occurred with contrast injection through the guiding catheter $(20 \mathrm{~mL}$ for left coronary system and $10-15 \mathrm{~mL}$ for the right coronary artery). Automated pullback was performed within the OCT imaging catheter when adequate distal coronary preparation had occurred. Additional runs were undertaken if required (suboptimal image quality) (see online supplementary figure s1).

The scans were anonymised and analysed (ILUMIEN PCI Optimization System, St Jude Medical, USA) in blinded fashion by two experienced operators (online supplementary figure s2). Analysis was performed at $1 \mathrm{~mm}$ intervals along the entire stented segment from the first distal frame with a stent strut present. A stent strut was considered suitable for analysis, if it was well defined with adequate shadow. For each calculated segment, total number of struts, malapposed struts (defined as $\geq 110 \mu \mathrm{m}$ from the vessel wall) or uncovered struts (no visual intimal coverage) were counted. Manual luminal and stented contours were drawn to calculate luminal and stented areas. For each cross-section area of luminal loss (in-stent stenosis (ISR)) was calculated as the average of:

$\frac{\text { Stented area }\left(\mathrm{mm}^{2}\right)-\text { Average Luminal Area }\left(\mathrm{mm}^{2}\right)}{\text { Stented area }\left(\mathrm{mm}^{2}\right)}$

Significant ISR by OCT was defined as angiographic assessment of ISR by the presence of $>50 \%$ of the diameter stenosis in the stented region. ${ }^{13}$

\section{Study end points}

Given that cadaveric studies have demonstrated that stent re-endothelialisation is an important factor in the pathophysiology of ST and provides a sensitive surrogate measure to conduct comparative studies. The primary end point was defined as $\%$ of uncovered stent struts by OCT at 6 months. This was used as a surrogate marker of endothelial coverage as it does not necessarily mean complete endothelisation.

Post hoc analysis included stent malapposition defined as struts with detachment from the vessel $\geq 110 \mu \mathrm{m}$ (as previously defined as a set distance for malapposition ${ }^{14}$ ) to establish a possible mechanistic explanation for the primary end point. Safety end points included subacute or late ST according to Academic Research Consortium definitions, ${ }^{15}$ the need for revascularisation of the stent segment and major adverse cardiovascular events (MACE) as defined as myocardial infarction, all-cause mortality and target vessel revascularisation.

\section{Statistical analysis}

The study was designed to compare the strut coverage at 6 months by OCT between ZES and EES second-generation DES. Calculation of sample size was based on demonstrating equivalency of ZES compared with EES platform at 6 months with respect to $\%$ strut coverage. Previous studies assessing ZES and EES strut coverage have demonstrated rates of uncovered struts of between $3.4 \%$ at 9 months and $6.2 \%$ at 3 months with SD reported of between 3 and $10 .{ }^{16-19}$ Assuming a coverage rate difference between stent types of no more than $6 \%$ and a $10 \%$ loss to follow-up, the sample size of 60 patients was estimated to provide $80 \%$ power and a $5 \%$ alpha error rate.

All statistical analyses were performed using SPSS V.21.0 (IBM, Armonk, New York, USA) and graphs produced using Graphpad Prism V.5.0 (GraphPad Software, San Diego, California, USA). Analysis was performed based on the intention-to-treat principle. Baseline demographics and clinical variables were summarised for each trial arm. Continuous variables are presented as means $\pm \mathrm{SD}$ and analysed with Student's t-test or paired t-test. Categorical variables are presented as numbers and percentages and analysed using $\chi^{2}$ statistics or Fisher's exact test. All $P$ values are two-sided and a value $<0.05$ was considered to indicate statistical significance.

\section{RESULTS}

Between 30 January 2012 and 10 July 2014, 805 patients with diabetes were screened for inclusion into the study. Of these patients, 105 were consented for the trial of which 45 were excluded following angiography due to the following reasons: coronary artery bypass grafting $(n=12)$, lesion outside inclusion parameters $(\mathrm{n}=9)$ and medical management $(n=24)$. Of the 700 patients excluded prior to consent, 198 patients declined to be part of the trial, the remaining 502 patients failed inclusion criteria. We therefore present the data for the 60 patients who were randomised equally between the EES and ZES groups.

The mean age of the total population was $61.45 \pm 10.71$ years and $75 \%$ were male. At baseline, both arms were similar with regard to age, sex, medical and diabetic therapy (table 1).

Both arms had similar distributions of target vessels and rates of multivessel PCI. A total of 46 patients attended the 6 months OCT (24 patients in the ZES group and 22 patients in the EES group) (figure 1).

\section{ZES versus EES analysis}

The total number of OCT cross-sections analysed was 1086 with a combined total of 11531 struts analysed. There was no significant difference between the total number of uncovered struts in the EES group (114 (2.4\%)) and the ZES group (84 (1.2\%)), $\mathrm{P}=0.31$ (figure 2, table 2).

There was no significant difference between the total number of malapposed stents in the EES group $(188(3.9 \%))$ and the ZES group (171 (2.5\%)), $\mathrm{P}=0.25$ (table 2). The individual cross-section ISR ranged from $0.68 \%$ to $51.35 \%$, with no difference between stent types with a median ISR of $13.03 \% \pm 7.27 \%$ in the EES group vs $13.51 \% \pm 9.40 \%$ in the ZES group, $\mathrm{P}=0.85$ (table 2 ). 
Table 1 Baseline characteristics of the OCT DES trial

\begin{tabular}{|c|c|c|c|}
\hline & ZES & EES & \multirow[b]{2}{*}{$P$ value } \\
\hline & $(n=30)$ & $(n=30)$ & \\
\hline Age (years) & $62.6 \pm 12.01$ & $59.20 \pm 9.81$ & 0.2345 \\
\hline Sex (male/female) & $23 / 7$ & $22 / 8$ & 0.7656 \\
\hline Ethnicity (Caucasian), n (\%) & $15(50 \%)$ & $14(46.7 \%)$ & 0.7961 \\
\hline Ethnicity (Asian), n (\%) & $14(46.7 \%)$ & $14(46.7 \%)$ & $>0.9999$ \\
\hline $\begin{array}{l}\text { Acute Coronary Syndrome (non-ST-elevation myocardial } \\
\text { infarction)/stable }\end{array}$ & $10 / 20$ & $13 / 17$ & 0.5959 \\
\hline \multicolumn{4}{|l|}{ Medical history } \\
\hline Hypertension (\%) & $25(83.3 \%)$ & $26(86.7 \%)$ & 0.7177 \\
\hline Hypercholesterolaemia (\%) & $23(76.7 \%)$ & $22(73.3 \%)$ & 0.7656 \\
\hline Type 2 diabetes mellitus (\%) & $15(100 \%)$ & $15(100 \%)$ & $>0.9999$ \\
\hline Active smoker (\%) & $7(23.3 \%)$ & $3(10 \%)$ & 0.1659 \\
\hline Previous myocardial infarction (\%) & $11(36.7 \%)$ & $12(40 \%)$ & 0.7906 \\
\hline Family history (\%) & $8(26.7 \%)$ & $7(23.3 \%)$ & 0.7656 \\
\hline \multicolumn{4}{|l|}{ Medical therapy } \\
\hline Aspirin (\%) & $15(100 \%)$ & $15(100 \%)$ & $>0.9999$ \\
\hline Clopidogrel (\%) & $18(60 \%)$ & $16(53.3 \%)$ & 0.6023 \\
\hline Statin $(\%)$ & $28(93.3 \%)$ & $27(90 \%)$ & 0.6404 \\
\hline ACEi (\%) & $21(70 \%)$ & $18(60 \%)$ & 0.4168 \\
\hline$\beta$-Blockers (\%) & $22(73.3 \%)$ & $23(76.7 \%)$ & 0.7656 \\
\hline \multicolumn{4}{|l|}{ Diabetes therapy } \\
\hline Diet control & $1(3.3 \%)$ & $2(6.7 \%)$ & 0.5923 \\
\hline Oral antiglycaemics & $20(66.7 \%)$ & $22(73.3 \%)$ & 0.5731 \\
\hline Combined insulin therapy & $9(30 \%)$ & $6(20 \%)$ & 0.3711 \\
\hline Baseline haemoglobin A1c IFCC (20-48) & $62.4 \pm 17.4$ & $61.8 \pm 17.9$ & 0.9137 \\
\hline \multicolumn{4}{|l|}{ Symptoms } \\
\hline New York Heart Association & $1.70 \pm 0.60$ & $1.83 \pm 0.91$ & 0.5056 \\
\hline Canadian Cardiovascular Society & $1.77 \pm 0.73$ & $2.00 \pm 0.71$ & 0.2170 \\
\hline \multicolumn{4}{|l|}{ Baseline observations } \\
\hline Pulse (bpm) & $67.07 \pm 11.64$ & $67.57 \pm 11.89$ & 0.8709 \\
\hline Systolic blood pressure $(\mathrm{mm} \mathrm{Hg})$ & $130.7 \pm 17.63$ & $131.0 \pm 24.41$ & 0.9541 \\
\hline Diastolic blood pressure (mm Hg) & $67.26 \pm 8.69$ & $69.61 \pm 9.50$ & 0.3439 \\
\hline Vessel treated & & & 0.2242 \\
\hline LAD & $16(53.3 \%)$ & $18(60 \%)$ & \\
\hline LCx & $6(20 \%)$ & $9(30 \%)$ & \\
\hline $\mathrm{RCA}$ & $8(26.7 \%)$ & $3(10 \%)$ & \\
\hline Multivessel PCI & $4(13.3 \%)$ & $6(20 \%)$ & 0.4884 \\
\hline
\end{tabular}

Plus-minus values are mean \pm SD.

Vessels treated $\mathrm{P}$ value assessed by $\chi^{2}$ test.

ACEi, ACE inhibitor; DES, drug-eluting stent; EES, everolimus-eluting stent; LAD, left anterior descending; LCx, left circumflex; n, number; $\mathrm{OCT}$, optical coherence tomography; PCI, percutaneous coronary intervention; RCA, right coronary artery; ZES, zotarolimus-eluting stent.

\section{Quantitative coronary angiography}

All patients underwent QCA analysis prior to PCI. The left anterior descending artery was the most commonly treated vessel, with significant difference in lesion complexity in relation to lesion length and \% stenosis. The mean greatest area of stenosis was $80.37 \% \pm 12.27 \%$ at baseline. Post-PCI, the calculated mean acute gain was $0.51 \pm 0.47 \mathrm{~mm}$, with mean late loss being $0.21 \pm 0.60 \mathrm{~mm}$. There was no significant difference between the baseline coronary stenosis in the EES group $82.15 \% \pm 13.47 \%$ and the ZES group $78.59 \% \pm 10.88 \%$, $\mathrm{P}=0.26$. There was no significant difference in coronary response to stent implantation, no significant difference in 


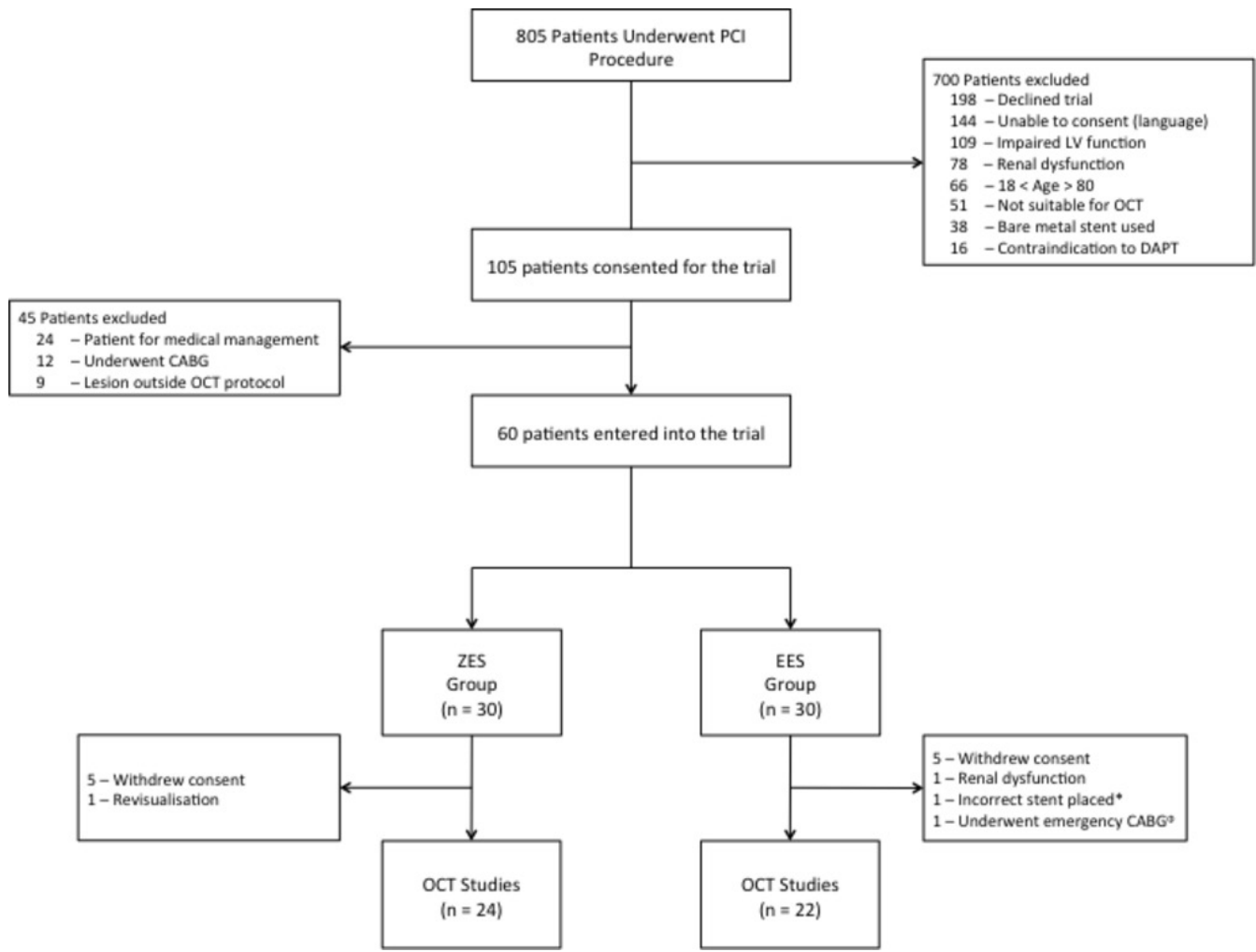

Figure 1 Consort diagram of the OCT DES trial. DES, drug-eluting stent; EES, everolimus-eluting stent; CABG, coronary artery bypass grafting; DAPT, dual antiplatelet therapy; LV, left ventricle; OCT, optical coherence tomography; PCl, percutaneous coronary intervention; ZES, zotarolimus-eluting stent.

acute loss between the stents in the EES group $0.59 \pm 0.45 \mathrm{~mm}$ and the ZES group $0.42 \pm 0.28 \mathrm{~mm}, \mathrm{P}=0.17$. At 6 months, there was a larger amount of late loss seen in the EES group

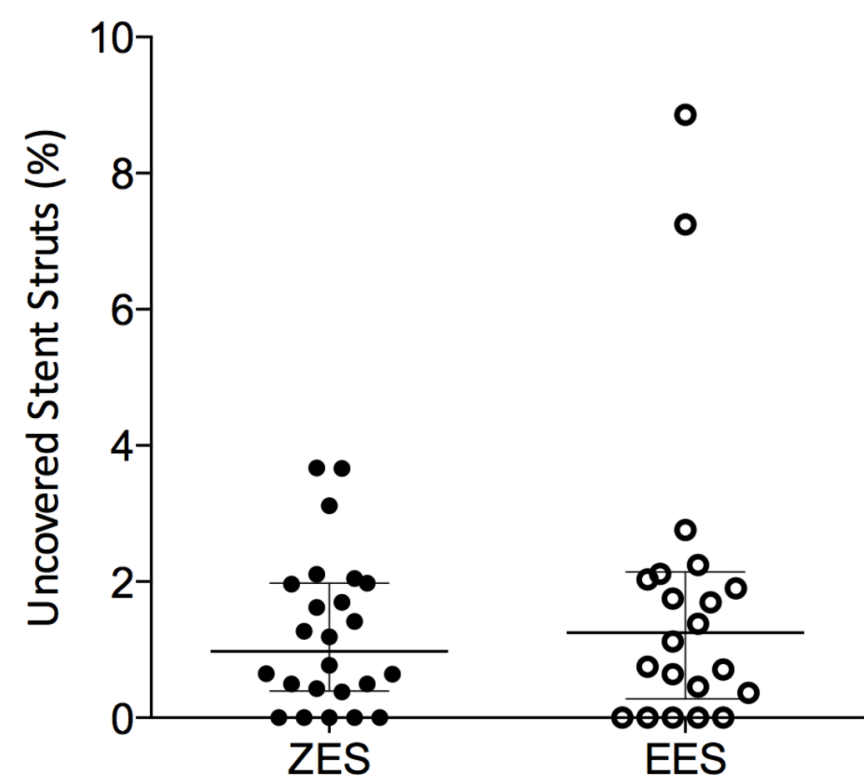

Figure 2 Comparison of prevalence of uncovered struts between ZES and EES groups. Scatter plot of uncovered stent strut (\%) as assessed by OCT between EES group and ZES group. No significance seen as evaluated using Mann-Whitney $\mathrm{U}$ test and data shown as median \pm IQR. EES, everolimus-eluting stent; OCT, optical coherence tomography; ZES, zotarolimus-eluting stent.
Table 2 Results of optical coherence tomography analysis

\begin{tabular}{llll}
\hline & ZES (n=24) & EES $(\mathbf{n}=22)$ & P value \\
\hline $\begin{array}{l}\text { Time to follow-up } \\
\text { (days) }\end{array}$ & 189 & 190 & 0.1039 \\
Total number of struts & 6744 & 4787 & 0.1177
\end{tabular}

(n)

\begin{tabular}{llll}
$\begin{array}{l}\text { Uncovered struts }(\mathrm{n} \\
(\%))\end{array}$ & $\begin{array}{l}84 \\
(1.2 \%)\end{array}$ & $\begin{array}{l}114 \\
(2.4 \%)\end{array}$ & 0.3090 \\
\hline $\begin{array}{l}\text { Malapposed struts }(\mathrm{n} \\
(\%))\end{array}$ & $\begin{array}{l}171 \\
(2.5 \%)\end{array}$ & $\begin{array}{l}188 \\
(3.9 \%)\end{array}$ & 0.2506 \\
$\begin{array}{l}\text { Mean neointimal } \\
\text { hyperplasia }(\mu \mathrm{m})\end{array}$ & $86.07 \pm 52.89$ & $82.17 \pm 54.09$ & 0.7787 \\
\hline $\begin{array}{l}\text { Total number of cross- } \\
\text { sections }(\mathrm{n})\end{array}$ & 582 & 504 & 0.6173 \\
$\begin{array}{l}\text { Mean measured stent } \\
\text { length (mm) }\end{array}$ & $22.97 \pm 9.48$ & $21.77 \pm 8.27$ & 0.6514 \\
\hline $\begin{array}{l}\text { Mean luminal area } \\
\left.(\mathrm{mm})^{2}\right)\end{array}$ & $5.87 \pm 2.51$ & $5.59 \pm 1.89$ & 0.6725 \\
\hline $\begin{array}{l}\text { Mean stented area } \\
\left(\mathrm{mm}^{2}\right)\end{array}$ & $6.67 \pm 2.52$ & $6.37 \pm 1.88$ & 0.6460 \\
\hline \begin{tabular}{l} 
Mean ISR (\%) \\
\hline
\end{tabular} & $13.51 \pm 9.40$ & $13.03 \pm 7.27$ & 0.8468 \\
\hline
\end{tabular}

$P$ value calculated using Mann-Whitney $U$ test.

Plus-minus values are mean \pm SD.

EES, everolimus-eluting stent; ISR, in-stent restenosis; $n$, number; OCT, optical coherence tomography; ZES, zotarolimuseluting stent. 


\begin{tabular}{|c|c|c|c|}
\hline & ZES & EES & \\
\hline Baseline & $(n=30)$ & $(n=30)$ & \\
\hline Follow-up & $(n=24)$ & $(n=22)$ & $P$ value \\
\hline \multicolumn{4}{|l|}{ Procedure } \\
\hline $\begin{array}{l}\text { Reference vessel } \\
\text { diameter (mm) }\end{array}$ & $2.18 \pm 0.40$ & $2.38 \pm 0.59$ & 0.1343 \\
\hline $\begin{array}{l}\text { Length of stenosis } \\
(\mathrm{mm})\end{array}$ & $14.2 \pm 5.09$ & $14.1 \pm 6.41$ & 0.9328 \\
\hline Area stenosis (\%) & $78.59 \pm 10.88$ & $82.15 \pm 13.47$ & 0.2647 \\
\hline $\begin{array}{l}\text { Maximum balloon } \\
\text { diameter }(\mathrm{mm})\end{array}$ & $2.81 \pm 0.46$ & $2.65 \pm 0.52$ & 0.2373 \\
\hline $\begin{array}{l}\text { Poststent insertion } \\
\text { stenosis (\%) }\end{array}$ & $14.88 \pm 7.04$ & $18.03 \pm 12.02$ & 0.2197 \\
\hline Improved stenosis & $65.55 \pm 15.00$ & $63.48 \pm 15.38$ & 0.6011 \\
\hline Acute loss (mm) & $0.42 \pm 0.48$ & $0.59 \pm 0.45$ & 0.1669 \\
\hline \multicolumn{4}{|l|}{ Follow-up } \\
\hline Area stenosis (\%) & $40.83 \pm 21.46$ & $39.58 \pm 21.16$ & 0.8415 \\
\hline $\begin{array}{l}\text { Stent diameter } \\
\text { reduction (\%) }\end{array}$ & $-5.52 \pm 27.65$ & $-13.05 \pm 22.63$ & 0.3130 \\
\hline Late loss (mm) & $0.06 \pm 0.50$ & $0.36 \pm 0.66$ & 0.0833 \\
\hline
\end{tabular}

Plus-minus values are mean \pm SD.

EES, everolimus-eluting stent; n, number; ZES, zotarolimuseluting stent.

$0.36 \pm 0.66 \mathrm{~mm}$ versus the ZES group $0.06 \pm 0.50 \mathrm{~mm}$; however, this did not reach statistical significance (table 3 ).

\section{Symptoms}

At 6 months OCT was performed on 46 patients with a mean number of cross-sections analysed per patient of $23.61 \pm 8.95$. In these patients, the median ISR was $13.00 \%$ (IQR 7.45-16.54). A total of 19 patients who underwent OCT assessment had symptoms either New York Heart Association $>2$ or Canadian Cardiovascular Society $>1$. Significant ISR at 6 months was seen in 15\% (9) patients with no significant difference seen in either rates of significant ISR or symptoms between the two stent types.

\section{MACE rates}

The overall incidence of MACE rates at 6 months was $8.2 \%(\mathrm{n}=4)$. In two events, the cause was a non-ST-elevation myocardial infarction requiring further PCI; one was her revascularisation based on anginal symptoms; one was due to a ST-elevation myocardial infarction due to incomplete stent expansion secondary to heavily calcified coronary artery and resulted in stent thrombus at day 3 postimplantation. Of these four patients, 6 months follow-up OCT evaluation was not performed in three of these patients (figure 3A). There was no significant difference in MACE seen between the two groups, with one $(3.3 \%)$ MACE in the EES group (one myocardial infarction) and three (10\%) in the ZES groups (two myocardial infarctions and one revascularisation), $\mathrm{P}=0.24$ (figure 3B).
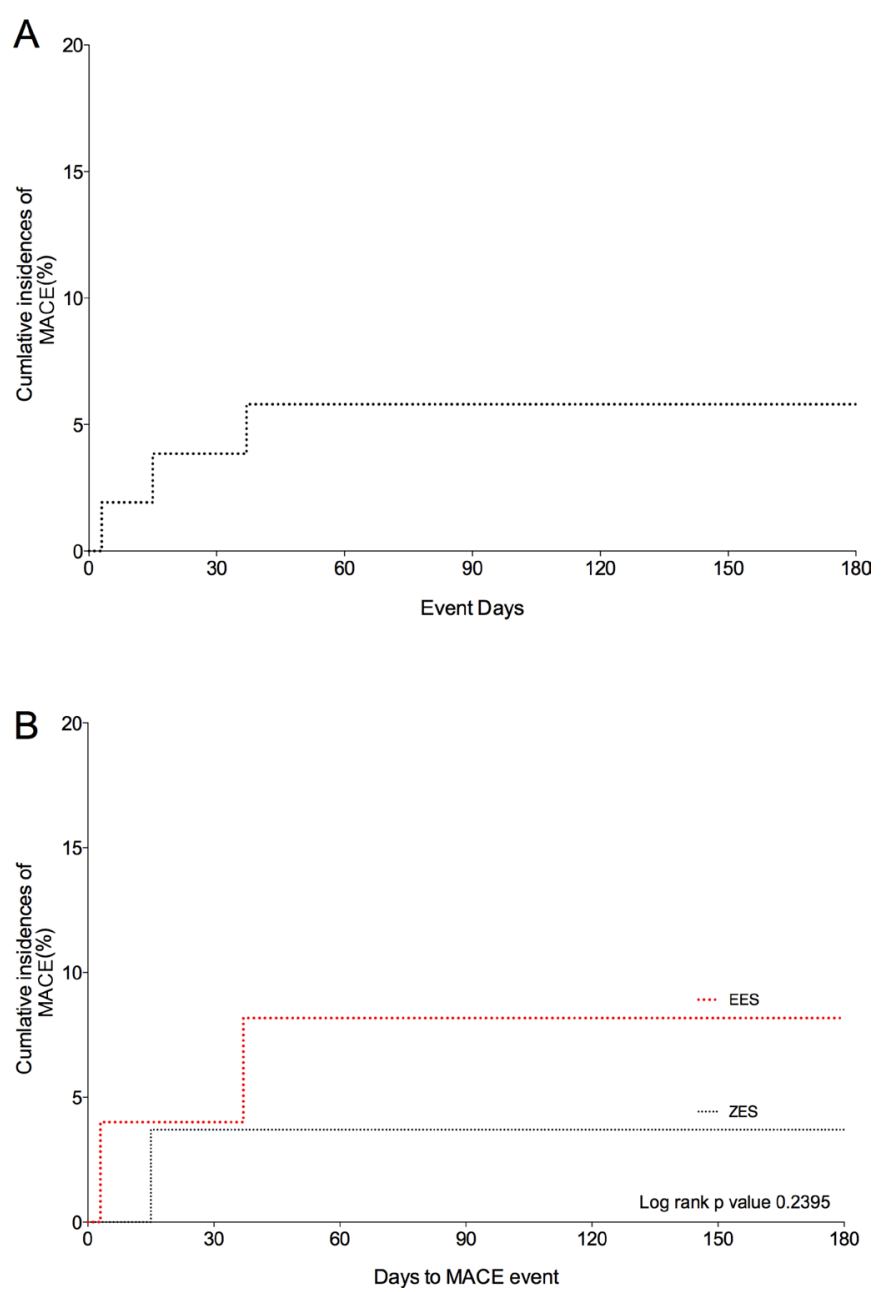

Figure 3 Major adverse cardiovascular events (MACE). (A) Combined MACE; (B) MACE between EES and ZES groups. EES, everolimus-eluting stent; ZES, zotarolimuseluting stent.

\section{OCT analysis reproducibility}

Stent strut assessment showed low interobserver variability, with good correlations between analysers for both the number of struts assessed $(r=0.9641, \mathrm{P}<0.0001)$ (figure $4 \mathrm{~A}$ ) and the number of uncovered struts $(\mathrm{r}=0.9111$, $\mathrm{P}<0.0001)$. The ISR assessment showed low interobserver variability, with the Bland-Altman plot, the $95 \%$ limits of agreement $\left(-0.100 \mathrm{~mm}^{2}, 0.089 \mathrm{~mm}^{2}\right)$ contained $94.8 \%$ of the difference scores (figure 4B). The mean bias of the measurements between observers was $-0.0053 \mathrm{~mm}^{2}$, and the maximum and minimum difference was 0.09 and $-0.10 \mathrm{~mm}^{2}$, respectively.

\section{DISCUSSION AND LIMITATIONS}

To our knowledge, this is the first randomised study to evaluate commercially available ZES and EES in patients with diabetes using advanced intravascular imaging (OCT) as the primary end point. This demonstrated that overall second-generation DES use appears safe and effective in patients with DM, with comparable low rates 
A

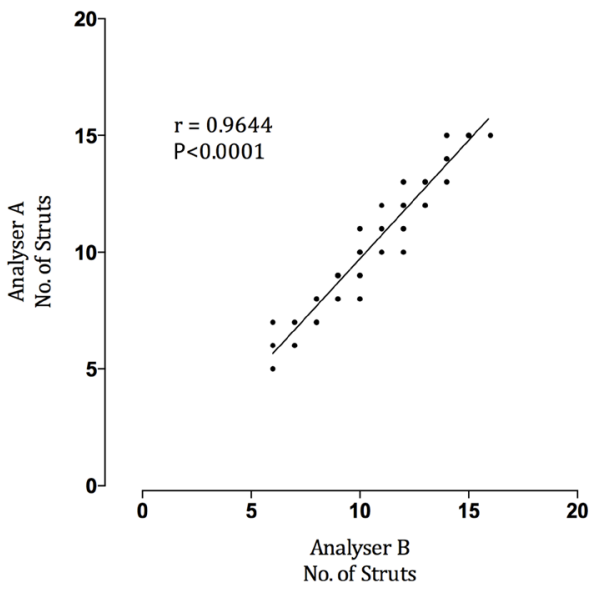

B

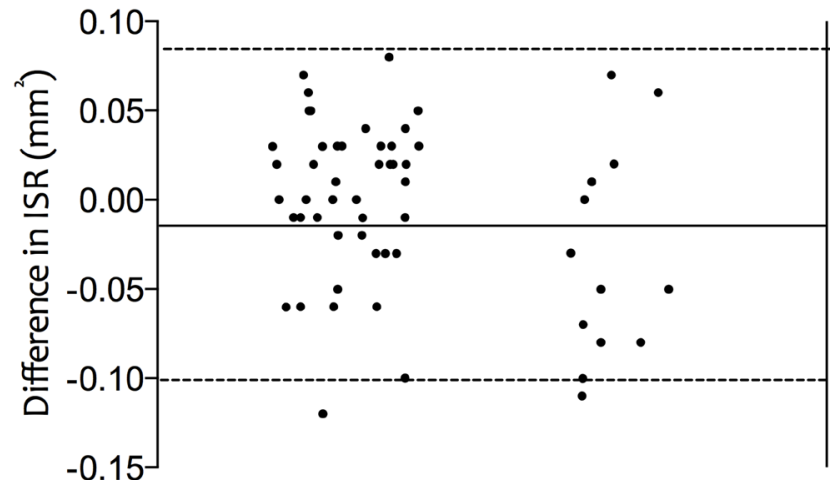

Figure 4 A) Relationship between analysis assessment of number of struts analysed. B) Bland-Altman plot for the interobserver variability for in-stent restenosis (ISR) percentage and interobserver correlation of strut numbers.

of uncovered stent struts at 6 months seen in both stent types.

The diabetic population is known to be at greater risk of increased cardiovascular events after PCI, especially in early BMS and first-generation DES. Previous studies have demonstrated increased risk of late in-stent thrombosis in patients ${ }^{20}$ with uncovered struts and autopsy studies demonstrating the ratio of uncovered struts as a predictor for late ST and restenosis. ${ }^{21}$ It has been previously shown by Tanaka et al that there is significantly higher neointimal coverage thickness when DES are implanted in patients with DM as compared with patients without DM. ${ }^{22}$ There have been mixed results when assessing different generation of DES, for the majority of these trials they have failed to demonstrate a significant difference between the two sent types, although some have shown significant differences in small population studies. ${ }^{12}$ In our study, we demonstrated that ZES and EES have similar numbers of uncovered stent struts at 6 months, with this relationship between uncovered struts and malaposition playing a vital role in re-endothelialisation. Our study reflects well with previous studies assessing commercially available stents that have been assessed in the general population. ${ }^{23} 24$

The result demonstrating no difference between the stent types is not unexpected. The eluted drugs that are present in this study have been widely used as an immunosuppressive for stents for over a decade and the prevention of organ rejection post-transplantation for longer. ${ }^{25} 26$ Both eluted drugs have been used in both diabetic and non-diabetic populations without any significant side effects or complications and therefore it is unlikely that a single drug would show benefit in comparison to the other. The EES and ZES both have a different stent lattice designs and eluted drug with the ZES having a higher strut-to-surface area ratio in comparison to the EES. This difference in lattice design is easier to detect and assess with OCT and is reflected in our trial by greater number of stent struts assessed in that group. This difference in strut design and thickness has in the past been shown to influence thrombogenicity and in this case the difference in strut design and any resulting difference in mechanical recoil poststent insertion could account for the results seen. ${ }^{27}$ However, both the number of uncovered struts did not differ significantly between stent types and the angiographic assessment of acute luminal loss after stent insertion showed no single stent type had a superior reduced amount of acute loss.

The issues with OCT analysis are well documented, with the potential loss of analysis area due to guide wire artefact, with may affect up to $10 \%$ of analysis area in large vessel and blood pooling. Due to the relative quality of the OCT analysis, the assessment of both luminal and stented area is easily manually traced and therefore we would expect and have seen good intraobserver reliability. ${ }^{28}$ Although OCT remains regarded by many as a research tool, there is evidence to suggest that it is a superior tool for the evaluation of stent coverage after stent implantation. The introduction of OCT in part has been responsible for the reduction of dual antiplatelet therapy time and the assessment of new implantable stent techniques. However, due to the nature of OCT we are unable to ascertain if the strut coverage is related to re-endothelialisation or other pathological processes.

Nearly $20 \%$ of our population who underwent OCT had significant ISR at 6 months, and over half of these patients did not complain of any symptoms. The relative high proportion of asymptomatic patients who had significant ISR could potentially relate to the risk of a silent myocardial ischaemia. The rate of silent myocardial ischaemia in patients with diabetes has been demonstrated to be higher than in non-diabetic population. ${ }^{29}$ Therefore to reduce the rise of ISR, the clinical consideration should possibly be not the stent type that is inserted in the diabetic population but the quality of stent insertion with adequate coronary assessment during stent insertion. In comparison to previous DES studies, our trial reflects these larger trials well. The previous published TWENTE II and HOST-ASSURE (Harmonizing Optimal Strategy for Treatment of Coronary Artery Stenosis-Safety \& Effectiveness of DrugEluting Stents \& Anti-platelet Regimen) studies showed no significant difference in event rate and had a similar symptom profile seen. ${ }^{30} 31$ 
There are a few limitations in this trial. We only performed OCT at 6 months (not at baseline) and previous trials have demonstrated that there is a significantly better intracoronary result with baseline imaging techniques; however, the trial design was an attempt to reflect current clinical practice. ${ }^{24}$ In addition, there were a relatively high number of withdrawals with patients declining the OCT follow-up procedure that possibly could have resulted in bias; however, the follow-up numbers were not significantly different in either group with similar characteristics between those who did and did not undergo OCT follow-up. It is well described that with low sample sizes in randomised controlled trials can result in considerable limitation in power calculations. With the relatively high numbers of withdrawals, a power calculation was performed with the final number of patients showing that the study was powered at $80 \%$ with an error of 0.05 would detect a $3.6 \%$ difference in stent types. With the high number of dropouts and the prolonged requirement period, it could potentially lead to selection bias.

\section{CONCLUSION}

This study was the first randomised trial to evaluate OCT at 6 months for ZES and EES in patients with diabetes. Both stents showed near-complete strut stent coverage at 6 months, with no difference in ISR rates at 6 months. Although there was a high rate of patients with significant maximal ISR, there was no relationship between degree of maximal ISR \% and symptomatic involvement. Within daily practice on the basis of 6-month OCT follow-up imaging, we found that there were no differences in the rates of ISR between two commercially available stents. Therefore, we believe that our article contributes to improve clinical care in a high-risk group.

Acknowledgements The authors would like to thank interventional colleagues at Barts Heart Centre, St. Bartholomew's Hospital, including Andrew Deaner, Roshan Weerackody, Ajay Jain, Andrew Archbold, Andrew Wragg, Mark Westwood, Simon Kennon, Elliot Smith, Raj Amersey, David Wald, John Hogan, Rex Dawson, Paul Rees, Adam Timmis and Duncan Dymond; cardiac specialist nurses from the heart failure and cardiac rehabilitation teams; the nursing and junior medical staff of the cardiac catheterisation laboratory, coronary care unit and Riviere ward at the London Chest Hospital; cardiology colleagues from hospitals within the North East London Cardiac Network.

Contributors AK, AM and SMG conceived of the study. AK, AM, SMG and CJK initiated the study design and SH and DAJ helped with implementation. DAJ, SH, KSR and JL conducted recruitment and trial management. SH and AB performed imaging analysis. DAJ conducted the primary statistical analysis. All authors contributed to refinement of the study protocol and approved the final manuscript.

Funding This study was funded by an unrestricted grant from Medtronic.

Competing interests None declared.

Ethics approval The trial was approved by an independent ethics committee registered at approved registries (Clinicaltrials.gov: NCT02060357).

Provenance and peer review Not commissioned; externally peer reviewed.

Data sharing statement No current data are published in journals from this study. No further data are available for publication apart from this paper.

Open Access This is an Open Access article distributed in accordance with the Creative Commons Attribution Non Commercial (CC BY-NC 4.0) license, which permits others to distribute, remix, adapt, build upon this work non-commercially, and license their derivative works on different terms, provided the original work is properly cited and the use is non-commercial. See: http://creativecommons.org/ licenses/by-nc/4.0/

(C) Article author(s) (or their employer(s) unless otherwise stated in the text of the article) 2018. All rights reserved. No commercial use is permitted unless otherwise expressly granted.

\section{REFERENCES}

1. Shaw JE, Sicree RA, Zimmet PZ. Global estimates of the prevalence of diabetes for 2010 and 2030. Diabetes Res Clin Pract 2010;87:4-14.

2. Elezi S, Kastrati A, Pache J, et al. Diabetes mellitus and the clinical and angiographic outcome after coronary stent placement. J Am Coll Cardiol 1998;32:1866-73.

3. Cutlip DE, Chhabra AG, Baim DS, et al. Beyond restenosis: five-year clinical outcomes from second-generation coronary stent trials. Circulation 2004;110:1226-30.

4. Windecker S, Meier B. Late coronary stent thrombosis. Circulation 2007;116:1952-65.

5. Garg P, Normand SL, Silbaugh TS, et al. Drug-eluting or baremetal stenting in patients with diabetes mellitus: results from the Massachusetts Data Analysis Center Registry. Circulation 2008;118:2277-85

6. Mak K-H. Drug eluting stents for patients with diabetes. BMJ 2012;345:e5828.

7. Armstrong EJ, Rutledge JC, Rogers JH. Coronary artery revascularization in patients with diabetes mellitus. Circulation 2013;128:1675-85

8. Miyazawa A, Ako J, Hongo Y, et al. Comparison of vascular response to zotarolimus-eluting stent versus sirolimus-eluting stent: intravascular ultrasound results from ENDEAVOR III. Am Heart $J$ 2008;155:108-13.

9. Finn AV, Joner M, Nakazawa G, et al. Pathological correlates of late drug-eluting stent thrombosis: strut coverage as a marker of endothelialization. Circulation 2007;115:2435-41.

10. Park KW, Lee JM, Kang SH, et al. Everolimus-eluting Xience v/ Promus versus zotarolimus-eluting resolute stents in patients with diabetes mellitus. JACC Cardiovasc Interv 2014;7:471-81.

11. Romaguera R, Gómez-Hospital JA, Gomez-Lara J, et al. A Randomized Comparison of Reservoir-Based Polymer-Free Amphilimus-Eluting Stents Versus Everolimus-Eluting Stents With Durable Polymer in Patients With Diabetes Mellitus: The RESERVOIR Clinical Trial. JACC Cardiovasc Interv 2016;9:42-50.

12. Kubo T, Akasaka T, Tanimoto T, et al. Assessment of vascular response after drug-eluting stents implantation in patients with diabetes mellitus: an optical coherence tomography sub-study of the J-DESsERT. Heart Vessels 2016;31:465-73.

13. Teirstein PS, Massullo V, Jani S, et al. Catheter-based radiotherapy to inhibit restenosis after coronary stenting. $N$ Engl $J$ Med 1997;336:1697-703.

14. Tanigawa J, Barlis P, Di Mario C. Intravascular optical coherence tomography: optimisation of image acquisition and quantitative assessment of stent strut apposition. Eurolntervention 2007;3:128-36.

15. Cutlip DE, Windecker S, Mehran R, et al. Clinical end points in coronary stent trials: a case for standardized definitions. Circulation 2007; $115: 2344-51$

16. Kim JS, Kim JS, Kim TH, et al. Comparison of neointimal coverage of sirolimus-eluting stents and paclitaxel-eluting stents using optical coherence tomography at 9 months after implantation. Circ $J$ 2010;74:320-6.

17. Kim JS, Kim BK, Jang IK, et al. ComparisOn of neointimal coVerage betwEen zotaRolimus-eluting stent and everolimus-eluting stent using Optical Coherence Tomography (COVER OCT). Am Heart J 2012;163:601-7.

18. Izumi D, Miyahara M, Fujimoto $\mathrm{N}$, et al. Optical coherence tomography analysis of the stent strut and prediction of resolved strut malapposition at 3 months after 2nd-generation drug-eluting stent implantation. Heart Vessels 2016;31.

19. Kubo T, Akasaka T, Kozuma K, et al. Comparison of neointimal coverage between everolimus-eluting stents and sirolimus-eluting stents: an optical coherence tomography substudy of the RESET (Randomized Evaluation of Sirolimus-eluting versus Everolimuseluting stent Trial). Eurolntervention 2015;11:564-71.

20. Shaw E, Allahwala UK, Cockburn JA, et al. The effect of coronary artery plaque composition, morphology and burden on Absorb bioresorbable vascular scaffold expansion and eccentricity - A 
detailed analysis with optical coherence tomography. Int J Cardiol 2015;184:230-6.

21. Won H, Shin DH, Kim BK, et al. Optical coherence tomography derived cut-off value of uncovered stent struts to predict adverse clinical outcomes after drug-eluting stent implantation. Int $J$ Cardiovasc Imaging 2013;29:1255-63.

22. Tanaka N, Terashima M, Rathore S, et al. Different patterns of vascular response between patients with or without diabetes mellitus after drug-eluting stent implantation: optical coherence tomographic analysis. JACC Cardiovasc Interv 2010;3:1074-9.

23. Toušek $P$, Kočka $V$, Malý $M$, et al. Neointimal coverage and late apposition of everolimus-eluting bioresorbable scaffolds implanted in the acute phase of myocardial infarction: OCT data from the PRAGUE-19 study. Heart Vessels 2016;31:841-5.

24. Kim JS, Shin DH, Kim BK, et al. Randomized comparison of stent strut coverage following angiography- or optical coherence tomography-guided percutaneous coronary intervention. Rev Esp Cardiol 2015;68:190-7.

25. Piccolo R, Stefanini GG, Franzone A, et al. Safety and efficacy of resolute zotarolimus-eluting stents compared with everolimuseluting stents: a meta-analysis. Circ Cardiovasc Interv 2015;8:e002223.
26. Mabasa VH, Ensom MH. The role of therapeutic monitoring of everolimus in solid organ transplantation. Ther Drug Monit 2005;27:666-76.

27. Kolandaivelu K, Swaminathan R, Gibson WJ, et al. Stent thrombogenicity early in high-risk interventional settings is driven by stent design and deployment and protected by polymer-drug coatings. Circulation 2011;123:1400-9.

28. Patel NA, Stamper DL, Brezinski ME. Review of the ability of optical coherence tomography to characterize plaque, including a comparison with intravascular ultrasound. Cardiovasc Intervent Radiol 2005;28:1-9.

29. Kannel WB, Abbott RD. Incidence and prognosis of unrecognized myocardial infarction. An update on the Framingham study. $N$ Engl $J$ Med 1984;311:1144-7.

30. van der Heijden LC, Kok MM, Löwik MM, et al. Three-year safety and efficacy of treating all-comers with newer-generation Resolute Integrity or PROMUS Element stents in the randomised DUTCH PEERS (TWENTE II) trial. Eurolntervention 2017:12:2128-31.

31. Park KW, Kang S-H, Kang H-J, et al. A Randomized Comparison of Platinum Chromium-Based Everolimus-Eluting Stents Versus Cobalt Chromium-Based Zotarolimus-Eluting Stents in All-Comers Receiving Percutaneous Coronary Intervention. J Am Coll Cardiol 2014:63:2805-16. 